\title{
On the nature of the affective priming effect: Effects of stimulus onset asynchrony and congruency proportion in naming and evaluative categorization
}

\author{
AdriaAn Spruyt And Dirk Hermans \\ University of Leuven, Leuven, Belgium \\ JAN DE HOUWER \\ Ghent University, Ghent, Belgium \\ AND \\ Heleen Vandromme and Paul Eelen \\ University of Leuven, Leuven, Belgium
}

\begin{abstract}
In line with the hypothesis that affective priming of evaluative categorization responses is based on processes that operate at a response selection stage, it has been observed that increasing the proportion of congruent trials brings about increased affective priming effects at short stimulus onset asynchronies (SOAs) in the evaluative categorization task. In the present study, we orthogonally manipulated the congruency proportion $(.25, .50$, and $.75)$ and the SOA $(0,200$, and 1,000 msec) in the evaluative categorization task and a naming task. Results showed that at both short and long SOAs, the affective priming effect in the evaluative categorization task was influenced by the congruency proportion. In contrast, affective priming effects in the naming task were unaffected by the congruency proportion at short SOAs. This pattern of results provides corroborating evidence for the hypotheses (1) that different processes underlie the affective priming effect in the evaluative categorization task and the naming task and (2) that valenced stimuli can automatically preactivate the memory representations of other, affectively related stimuli.
\end{abstract}

Recent theories of affect and emotion propose that attitudes can become active automatically and that automatic affective stimulus processing can have an important impact on subsequent emotional, cognitive, and/or behavioral processes (e.g., Bargh, 1996; Bargh, Litt, Pratto, \& Spielman, 1989; Greenwald \& Banaji, 1995; Lazarus, 1991; LeDoux, 1989; Murphy \& Zajonc, 1993; Öhman, 1987, 1988; Ortony, Clore, \& Collins, 1988; Scherer, 1993; Zajonc, 1980, 1984). In line with these hypotheses, affective priming studies (see Klauer \& Musch, 2003, for a review) have demonstrated that valenced target stimuli are responded to more quickly after the presentation of an affectively related prime stimulus than after the presentation of an affectively unrelated prime stimulus. This affective priming effect has been found (1) when the stimulus onset asynchrony (SOA; i.e., the interval between the prime and the target) was short (e.g., Fazio, Sanbonmatsu, Powell, \& Kardes, 1986; Hermans, De Houwer, \& Eelen, 2001), (2) when all the procedural features that might induce a strategic evaluative processing goal were removed (e.g., Bargh, Chaiken, Raymond, \& Hymes, 1996; Spruyt,
Hermans, De Houwer, \& Eelen, 2002), (3) when a secondary memory load task depleted cognitive capacities (e.g., Hermans, Crombez, \& Eelen, 2000), and (4) even when the primes were presented subliminally (e.g., Draine \& Greenwald, 1998; Greenwald, Klinger, \& Liu, 1989; Greenwald, Klinger, \& Schuh, 1995; Hermans, Spruyt, De Houwer, $\&$ Eelen, 2003). Moreover, the affective priming effect has been demonstrated with a wide variety of stimulus materials, including words (e.g., Fazio et al., 1986), line drawings (e.g., Giner-Sorolla, García, \& Bargh, 1999), complex color pictures (e.g., Spruyt et al., 2002), odors (e.g., Hermans, Baeyens, \& Eelen, 1998), evaluatively conditioned stimuli (e.g., Spruyt, Hermans, De Houwer, \& Eelen, 2004), and novel stimuli (e.g., Duckworth, Bargh, Garcia, \& Chaiken, 2002). Hence, it has been concluded that humans are, indeed, endowed with an evaluative decision mechanism that allows them to automatically and unconditionally evaluate all incoming stimulus information (e.g., Spruyt et al., 2002).

Despite the fact that affective priming research has made progress in describing and documenting the occur- 
rence of the affective priming effect, disagreement exists concerning the nature of the underlying mechanism that is responsible for the observed effects. Whereas several researchers have claimed that the affective priming effect can be produced only by processes that operate at a response selection stage (e.g., De Houwer, Hermans, Rothermund, \& Wentura, 2002; Klauer, 1998; Klauer, Roßnagel, \& Musch, 1997; Klinger, Burton, \& Pitts, 2000; Musch, Klauer, \& Mierke, 2004; Rothermund \& Wentura, 1998; Wentura, 1999, 2000), others have argued that affective priming effects may also be produced by processes that operate at an encoding level (e.g., Bargh et al., 1996; Chen \& Bargh, 1999; De Houwer, Hermans, \& Spruyt, 2001; De Houwer \& Randell, 2004; Duckworth et al., 2002; Ferguson, Bargh, \& Nayak, 2005; Spruyt et al., 2002; see also Bargh, 1997).

According to such an encoding account of affective priming, affectively polarized prime stimuli preactivate the memory representations of affectively related targets, thus making it easier to encode targets with the same valence than to encode targets with a different valence. Alternatively, according to a response level account of affective priming, affective priming effects are assumed to be due to the fact that affectively polarized prime stimuli automatically trigger response tendencies that facilitate or interfere with target responding. Consider, for instance, a typical affective priming study (e.g., Fazio et al., 1986) in which participants are instructed to categorize the targets on the basis of their valence (i.e., the evaluative categorization task). In this task, affective priming can be attributed to Stroop-like response interference processes because variations in the relationship between the correct response and the (task-irrelevant) primes are perfectly confounded with variations in the similarity between the (task-irrelevant) primes and the (task-relevant) targets (De Houwer, 2003; Klauer et al., 1997; Musch et al., 2004; see also Logan, 1980). That is, whenever a prime is affectively related with a target (e.g., the prime TERRIFIC and the target word FRIEND), its valence will also match with the valence of the response that is required (e.g., "positive"). Conversely, whenever a prime is affectively unrelated with a target (e.g., the prime TERRIFIC and the target word CANCER), there will be a mismatch between the valence of the prime and the valence of the response that is required (e.g., "negative"). Therefore, if it is assumed that the primes automatically activate the response alternative that corresponds with their valence, performance will be expected to be superior on affectively congruent trials, as compared with affectively incongruent trials, as is typically observed.

It should be noted that a response level account and an encoding account of affective priming are not mutually exclusive. One could easily argue that both mechanisms are involved in affective priming (e.g., Fazio, 2001). Nevertheless, most researchers in the field consider it unlikely that affective priming is produced by processes that operate at the encoding level. The following empirical findings have contributed to this viewpoint.

First of all, it has been demonstrated by Klauer et al. (1997) that in the evaluative categorization task, the magnitude of the affective priming effect increases with increasing proportions of affectively congruent trials at short SOAs (i.e., 0 and $200 \mathrm{msec}$ ). If affective priming effects were due to processes that operate at an encoding level, one would not expect to find such congruency proportion (CP) effects (Klauer et al., 1997; Musch et al., 2004). Moreover, given that these CP effects emerged at very short SOAs, it seems unlikely that they were produced by slow-acting, expectancy-based response strategies (Klauer et al., 1997). Instead, Klauer and his colleagues proposed an explanation in terms of Logan and Zbrodoff's (1979) account for CP effects in the Stroop task (see also Cohen, Dunbar, \& McClelland, 1990; Lowe \& Mitterer, 1982; MacLeod, 1991). According to Logan and Zbrodoff, the state of evidence on which participants base their responses in the Stroop task can be expressed as a weighted sum of evidence that is available about the task-relevant stimulus dimension and the task-irrelevant stimulus dimension. Although both the weight of the taskrelevant stimulus dimension and the weight of the taskirrelevant stimulus dimension are assumed to reflect the operation of automatic processes to some extent, Logan and Zbrodoff also assumed that participants strategically adjust these weights through an act of attention when they learn that the CP is above or below chance level (.50). More specifically, they assumed that positive attentional weights are assigned to both the irrelevant stimulus dimension and the relevant stimulus dimension whenever the CP is above chance level. Alternatively, whenever the $\mathrm{CP}$ is below chance level, they assumed that a negative attentional weight is assigned to the irrelevant stimulus dimension and a positive attentional weight is assigned to the relevant stimulus dimension. As a result, Stroop effects are expected to increase when the $\mathrm{CP}$ rises above .50 and to decrease when the $\mathrm{CP}$ drops below .50, a pattern of results that Logan and Zbrodoff, indeed, repeatedly obtained.

Klauer et al. (1997) pointed out that the same logic can be applied to the $\mathrm{CP}$ effects that they obtained at short SOAs with the evaluative categorization task. Indeed, if it is assumed that participants strategically divide their attention between the primes (the irrelevant stimuli) and the targets (the relevant stimuli), CP effects in the evaluative categorization task are a natural consequence of the assumption that participants assign greater attentional weights to the primes when they learn that the $\mathrm{CP}$ is above or below chance level. Moreover, because it is assumed that the attentional weights are assigned on the basis of the overall $\mathrm{CP}$, the attentional weights are assumed to be set as soon as the perceiver has learned what the overall $\mathrm{CP}$ is. The model of Logan and Zbrodoff (1979) can, therefore, explain the occurrence of $\mathrm{CP}$ effects in the evaluative categorization task at short SOAs. Accordingly, Klauer et al. (1997) concluded that "the Stroop paradigm is a more appropriate point of reference for affective priming in the evaluative categorization task than the semantic priming paradigm" (p. 253), an interpretation that they recently reiterated on the basis of new experimental findings (Musch et al., 2004).

Wentura (1999) also obtained evidence that is consistent with the hypothesis that the affective priming ef- 
fect in the evaluative categorization task is based on a Stroop-like response conflict. It is known, from research with Stroop-like paradigms, that responding on trial $n$ is delayed when the relevant stimulus feature on trial $n$ is related to the irrelevant stimulus feature on trial $n-1$ (i.e., negative priming; for reviews, see Fox, 1995; May, Kane, $\&$ Hasher, 1995). For example, it has been observed that participants need more time to name a color of a Stroop color-word stimulus (e.g., the color red) when that color corresponds to the word that had to be ignored on the previous trial (e.g., the word RED written in green ink; see, e.g., Dalrymple-Alford \& Budayr, 1966). Such an effect can be explained if it is assumed that a response conflict on trial $n-1$ results in a suppression of the response alternative that is triggered by the irrelevant stimulus feature. If the information that was irrelevant on trial $n-1$ is then relevant on trial $n$, this inhibition needs to be overcome, and responses will be delayed. Wentura (1999) showed that similar effects occur in the evaluative categorization task. He observed that the time needed to categorize the targets on the basis of their valence increased when the valence of the targets matched with the valence of an incongruent prime on the previous trial.

Finally, the hypothesis that affective priming effects are based on processes that operate at a response selection stage is also supported by several studies in which participants were asked to respond on the basis of a nonaffective stimulus feature. On the basis of a response account of affective priming, one would not expect to observe affective priming effects in such response tasks, simply because affectively congruent and affectively incongruent primes cannot influence response selection differentially when responses are unrelated to stimulus valence. In line with the idea that affective priming effects are produced by processes that operate at a response stage, De Houwer et al. (2002) and Klinger et al. (2000) failed to observe significant affective priming effects when participants were asked to categorize the targets on the basis of a nonaffective semantic feature (e.g., animate or inanimate), whereas strong affective priming effects occurred when participants were asked to respond on the basis of the valence of the targets. Likewise, several studies in which participants were asked to name target words also failed to produce significant affective priming effects (e.g., De Houwer, Hermans, \& Eelen, 1998; Hermans, 1996, Experiment 8; Klauer \& Musch, 2001; Spruyt, Hermans, Pandelaere, De Houwer, \& Eelen, 2004; but see Bargh et al., 1996; Hermans, De Houwer, \& Eelen, 1994). It would be difficult to explain affective priming of naming responses on the basis of processes that operate at a response selection stage because, in the naming task, the correct response on any given trial depends on the identity of the target, rather than on the valence of the target (but see Rothermund \& Wentura, 1998). Hence, failures to replicate the affective priming effect in the naming task are also consistent with the hypothesis that affective priming effects are based on processes that operate at a response selection stage.

However, recent studies suggest that reliable affective priming of naming responses can, nevertheless, be ob- tained when procedures are used that increase the extent to which naming is semantically mediated. For example, De Houwer and Randell (2004) recently showed that significant affective priming effects can be found in a wordnaming task when participants are asked to name only those target words that belong to a specific semantic category. Because such an effect was not found when word naming was made conditional upon the detection of a (nonsemantic) perceptual feature of the target words, De Houwer and Randell concluded that the affective relationship between a prime and a target will influence the naming of the target word only if and to the extent that semantic information can feed into the orthography-to-phonology translation process (see also De Houwer et al., 2001). Spruyt et al. (2002) also obtained evidence that suggests that naming responses can be affectively primed. They observed significant affective priming effects in a picture-naming task when pictures were used as primes, but not when words were used as primes. Spruyt et al. (2002) had predicted these results on the basis of the model of W. R. Glaser and M. O. Glaser (1989). According to this model (see also W. R. Glaser, 1992), pictures have privileged access to a semantic system that contains all semantic knowledge, whereas words first need to access a nonsemantic lexical system before they can activate semantic stimulus information. If it is assumed that affective information is stored within the semantic system (e.g., Bower, 1991; De Houwer \& Hermans, 1994; De Houwer \& Randell, 2004; Fiske \& Pavelchak, 1986), reliable affective priming effects are thus expected to occur in the picture-picture naming paradigm, as was observed.

Because it is difficult to explain affective priming of naming responses on the basis of a response level account (see above), both De Houwer and Randell (2004) and Spruyt et al. (2002) argued that their findings provide supporting evidence for the hypothesis that processes operating at an encoding level contribute to the affective priming effect (see also Duckworth et al., 2002). However, up to now, this hypothesis has never been subjected to a direct experimental analysis. ${ }^{1}$ Therefore, we set up an experiment in which we orthogonally manipulated the CP $(.25$, .50 , and .75) and the SOA $(0,200$, and 1,000 msec) in both the naming task and the evaluative categorization task. We reasoned that if affectively polarized stimuli automatically preactivate the memory representations of affectively related stimuli, the affective priming effect in the naming task should be unaffected by the CP at short SOAs (Klauer et al., 1997; Musch et al., 2004). Conversely, assuming that the affective priming effect in the evaluative categorization task is (at least partially) produced by a Stroop-like response competition mechanism, we expected to find a significant CP effect in the short-SOA conditions of the evaluative categorization task (Klauer et al., 1997; see also Logan \& Zbrodoff, 1979).

We had no explicit expectations, however, about what we would observe in the long-SOA conditions. Whereas several studies have shown that affective priming effects disappear at long SOAs (e.g., Fazio et al., 1986; Hermans et al., 2001), Klauer et al. (1997) obtained sig- 
nificant contrast effects (i.e., shorter response latencies on affectively unrelated trials than on affectively related trials) that were unaffected by the $\mathrm{CP}$ in the long-SOA condition of their Experiment 2. Klauer et al. (1997) hypothesized that this pattern of results may have been due to the fact that the participants attempted to actively (over)correct for the influence of the primes when the SOA was long (see also J. Glaser \& Banaji, 1999; Greenwald \& Banaji, 1995; Strack, Schwarz, Bless, Kübler, \& Wänke, 1993). On the other hand, one could also expect slow-acting, expectancy-based response strategies to produce CP effects at long SOAs (see de Groot, 1984; den Heyer, Briand, \& Dannenbring, 1983; Neely, 1977; Neely, Keefe, \& Ross, 1989; Perea \& Rosa, 2002; Seidenberg, Waters, Sanders, \& Langer, 1984; Tweedy, Lapinski, \& Schvaneveldt, 1977). Accordingly, we did not have explicit predictions about the results that would emerge in the long-SOA conditions of our experiment. Note, however, that the present experiment was primarily designed to study CP effects at short SOAs. A CP effect is the linear increase in the magnitude of the priming effect as a function of the CP. Thus, the statistical tests of central interest are the a priori contrasts that code a linear trend as a function of the CP.

\section{METHOD}

\section{Participants}

The participants were 180 University of Leuven students (35 men, 145 women). They received course credit for their participation. All the participants were native speakers of Dutch and had normal or corrected-to-normal vision.

\section{Design}

Task (naming vs. evaluative categorization) and CP (.25 vs. .50 vs. .75) were varied orthogonally as between-subjects variables ( $n=$ 30 in each between condition). SOA (0 vs. 200 vs. 1,000 msec) and affective congruency (congruent vs. incongruent) were varied orthogonally as within-subjects variables.

\section{Materials}

Positive and negative pictures were used as primes and targets. All the pictures were selected on the basis of a preliminary rating study in which participants $(N=51)$ rated the affective connotation of 215 real-life color pictures on an 11-point rating scale ranging from -5 (very negative) to +5 (very positive). ${ }^{2}$ Pictures that were selected as targets ( 8 positive and 8 negative) could be unambiguously named with a single word, whereas pictures that were selected as primes ( 6 positive and 6 negative) portrayed more complex real life scenes that could not be named with a single word. A listing of the target names and a description of the prime stimuli are provided in the Appendix.

Positive target pictures were evaluated more positively than were negative target pictures $\left[M_{\text {negative }}=-2.46, S E=0.13 ; M_{\text {positive }}=\right.$ $2.19, S E=0.06 ; t(14)=11.40, p<.001]$. Likewise, positive prime pictures were evaluated more positively than were negative prime pictures $\left[M_{\text {negative }}=-2.31, S E=0.14 ; M_{\text {positive }}=2.60, S E=0.10\right.$; $t(10)=11.50, p<.001]$. All the pictures were presented against the black background of a 19-in. computer monitor $(100 \mathrm{~Hz})$ and were 380 pixels wide and 285 pixels high ( 24 bits per pixel; screen resolution, 1,024 × 768)

An Affect 3.0 program (Hermans, Clarysse, Baeyens, \& Spruyt, 2003) controlled the presentation of the stimuli, as well as the registration of the response latencies. The experiment was run on a Pentium III 650-MHz computer.

\section{List Construction}

For each level of SOA, three blocks of 32 prime-target pairs were presented. These 96 trials were semirandomly sampled without replacement from the pool of available prime-target pairs (12 primes $\times 16$ targets $=192$ possible prime-target pairs), with the following restrictions: In each block, (1) all the targets were presented twice, (2) each prime was presented at least twice and at most four times, (3) trials with a positive prime and a positive target $(+,+)$ occurred as often as trials with a negative prime and a negative target $(-,-)$, and (4) trials with a negative prime and a positive target $(-,+)$ occurred as often as trials with a positive prime and a negative target $(+,-)$. In the $.25-\mathrm{CP}$ condition, one block contained $4(-,-)$ trials, $4(+,+)$ trials, $12(-,+)$ trials, and $12(+,-)$ trials. In the $.50-\mathrm{CP}$ condition, one block contained $8(-,-)$ trials, $8(+,+)$ trials, $8(-,+)$ trials, and $8(+,-)$ trials. In the $.75-\mathrm{CP}$ condition, one block contained $12(-,-)$ trials, $12(+,+)$ trials, $4(-,+)$ trials, and 4 $(+,-)$ trials. These semirandomizations were repeated for each level of SOA. The order of the SOA levels was counterbalanced across participants. The participants were not informed of the CP.

\section{Procedure}

The participants were randomly assigned to the six task $\times \mathrm{CP}$ conditions. They were tested individually in a dimly lit and soundproof room. All the instructions were presented on the computer screen, and all the participants were informed that they were participating in a picture recognition experiment.

Each trial started with a 500-msec presentation of a fixation cross in the center of the screen. Five hundred milliseconds after the offset of the fixation cross, the prime was presented for $200 \mathrm{msec}$. In the 0 -msec-SOA condition, the target pictures were presented simultaneously with the prime. In the 200-msec-SOA condition, the target pictures were presented at the offset of the prime. In the 1,000-msecSOA condition, the target pictures were presented $800 \mathrm{msec}$ after the prime offset.

Because of the overlap in the presentation of the primes and the targets in the 0-msec-SOA condition, we presented the primes and the targets above one another in all the SOA conditions. For each trial, it was randomly determined whether the prime was presented above or below the target, thus ensuring locational uncertainty (see Musch \& Klauer, 2001). When a picture was presented in the upper location, its underside was presented 37 pixels above the center of the computer screen. When a picture was presented in the lower location, its top side was presented 37 pixels below the center of the computer screen. In order to make it possible for the participants to discriminate between the primes and the targets when the SOA was $0 \mathrm{msec}$, the target pictures were always framed with a green rectangle.

In all the conditions, the targets were presented until the participant gave a response or $2,000 \mathrm{msec}$ had elapsed. In the naming conditions, the experimenter coded whether the microphone was accurately triggered and whether the participant's response was correct by pressing one of three keys on the computer keyboard. After the experimenter had entered the code, the next trial was initiated after a time interval that varied randomly between 500 and $1,500 \mathrm{msec}$. In the evaluation conditions, erroneous responses were registered by the computer. The intertrial interval in the evaluation conditions varied randomly between 500 and $1,500 \mathrm{msec}$.

In the naming conditions, there were two practice phases prior to the start of the experiment. During the first practice phase, the 16 target pictures were presented in a random order, with their corresponding names written underneath them. The participant was asked to look attentively at the pictures and at the corresponding names, because he or she would need to use these words to name the pictures correctly during the experimental phase of the experiment. The pictures remained on the screen until the participant pressed the space bar of the keyboard. At the end of the first practice phase, the keyboard was removed, and a microphone was placed in front of the participant. During the second practice phase, the 16 targets were presented again in a random order, but this time without the 
corresponding names written underneath them. The participant was instructed to name the pictures as quickly as possible. He or she was instructed to use the names that had been learned during the preceding series of practice trials. The pictures remained on the screen until the participant gave a response. When a target was named incorrectly, the experimenter corrected the participant. The next practice trial was initiated $1,500 \mathrm{msec}$ after the experimenter had entered a code.

In the evaluation conditions, there was only one practice phase. During this practice phase, the participant was asked to watch a random presentation of the 16 target pictures and to evaluate them as quickly as possible by pressing one of two keys. When a target was evaluated incorrectly, a short message was displayed that corrected the participant.

After completing the practice phases, the instructions for the experimental trials were displayed on the computer screen. In all the conditions, the participants were told that pairs of pictures would be presented on the computer screen. They were instructed to attend only to the pictures that were framed with a green rectangle and to respond to these pictures as quickly as possible. The participants were allowed to take a small break after completion of each SOA condition. During this break, a message on the computer screen stressed the importance of responding as quickly as possible. In order to familiarize the participants with the variations in the SOA, each SOA condition started with the presentation of four dummy trials [one $(+,+)$ trial, one $(+,-)$ trial, one $(-,+)$ trial, and one $(-,-)$ trial]. These dummy trials were randomly sampled (with replacement) from the pool of available prime-target pairs. For each dummy trial, it was randomly determined whether the prime was presented above or below the target. The ordering of the dummy trials was also randomized.

\section{RESULTS}

\section{Data Reduction and Analyses}

Both reaction time data and error data were analyzed. One participant who had been assigned to the $.25-\mathrm{CP}$ condition of the evaluative categorization task made an unusually high percentage of errors on affectively incongruent trials when the SOA was 0 msec (i.e., 81.94\%). ${ }^{3}$ The data of this participant were excluded from all the analyses. Data from naming trials on which the voice key was not appropriately activated $(2.84 \%)$ were also discarded. In addition, data from trials on which an incorrect response was given $(2.84 \%$ in the naming conditions, $5.51 \%$ in the evaluation conditions) were not included in the reaction time analyses. Finally, for the analysis of the reaction time data, the impact of outliers was reduced by removing response latencies that deviated more than 2.5 standard deviations from a participant's conditional mean latency (1.29\% in the naming conditions, $1.63 \%$ in the evaluation conditions). After calculating mean response latencies and mean percentages of errors for each participant and for each experimental condition, the data were analyzed by means of a five-way MANOVA (task $\times \mathrm{CP} \times \mathrm{SOA} \times$ block $\times$ affective congruency).

\section{Reaction Time Data}

Detailed descriptive statistics, as well as significance tests for the affective priming effects in each task $X$ $\mathrm{CP} \times \mathrm{SOA}$ condition (two-tailed $t$ tests), are provided in Table 1 . The main effect of affective congruency reached significance $[F(1,173)=69.72, p<.001]$ and proved to be significant in both the evaluative categorization task $[F(1,173)=41.24, p<.001]$ and the naming task $[F(1,173)=28.98, p<.001]$. Most important, the crucial three-way interaction between task, affective congruency, and $\mathrm{CP}$ also reached significance $[F(2,173)=$ $17.19, p<.001]$. As was expected, planned comparisons revealed that this three-way interaction was due to the fact that the difference between affectively congruent and affectively incongruent trials increased as a function of increasing levels of $\mathrm{CP}$ in the evaluative categorization task $[F(1,173)=60.38, p<.001]$, but not in the naming task $(F<1)$. Accordingly, separate analyses were performed for each task to assess the $\mathrm{CP}$ effects in more detail. In the evaluative categorization task, the linear effect of the $\mathrm{CP}$ on the magnitude of the affective congruency effect was significant in the 0 -msec-SOA condition $[F(1,86)=17.80, p<.001]$, the 200 -msec-SOA condition $[F(1,86)=22.57, p<.001]$, and the $1,000-\mathrm{msec}-$ SOA condition $[F(1,86)=22.41, p<.001]$. In contrast, $\mathrm{CP}$ effects were absent in all three SOA conditions for the naming task $(F \mathrm{~s}<1) .4$

The overall MANOVA also revealed a significant twoway interaction between affective congruency and SOA $[F(2,172)=27.80, p<.001]$. One-degree-of-freedom contrasts showed that the effect of affective congruency was significant in the 0 -msec-SOA condition $[F(1,173)=$ $44.83, p<.001]$ and the 200-msec-SOA condition $[F(1,173)=91.61, p<.001]$, but not in the 1,000 -msecSOA condition $(F<1)$. Interestingly, the three-way interaction between task, SOA, and affective congruency also reached significance $[F(2,172)=5.41, p<.01]$. Further

Table 1

Reaction Time Data: Mean Response Latencies (in Milliseconds) and Mean Affective Priming Effects (APEs) As a Function of Response Condition, Stimulus Onset Asynchrony (SOA), Congruency Proportion (CP), and Affective Congruency

\begin{tabular}{|c|c|c|c|c|c|c|c|}
\hline \multirow{3}{*}{$\begin{array}{c}\text { SOA } \\
(\mathrm{msec})\end{array}$} & \multirow[b]{3}{*}{$\mathrm{CP}$} & \multicolumn{4}{|c|}{ Affective Congruency } & & \\
\hline & & \multicolumn{2}{|c|}{ Congruent } & \multicolumn{2}{|c|}{ Incongruent } & \multicolumn{2}{|c|}{ APE } \\
\hline & & $M$ & $S E$ & $M$ & $S E$ & $M$ & $S E$ \\
\hline \multicolumn{8}{|c|}{ Naming } \\
\hline \multirow[t]{3}{*}{0} & .25 & 662 & 12 & 682 & 10 & $20^{* *}$ & 5 \\
\hline & .50 & 670 & 12 & 688 & 10 & $18^{* *}$ & 5 \\
\hline & .75 & 685 & 11 & 698 & 12 & $13^{*}$ & 7 \\
\hline \multirow[t]{3}{*}{200} & .25 & 639 & 11 & 649 & 10 & $10^{*}$ & 4 \\
\hline & .50 & 633 & 10 & 647 & 10 & $14^{* * *}$ & 3 \\
\hline & .75 & 642 & 11 & 653 & 13 & $11^{*}$ & 5 \\
\hline \multirow[t]{3}{*}{1,000} & .25 & 588 & 11 & 588 & 9 & 0 & 4 \\
\hline & .50 & 585 & 9 & 586 & 9 & 1 & 3 \\
\hline & .75 & 592 & 10 & 590 & 12 & -2 & 4 \\
\hline \multicolumn{8}{|c|}{ Evaluation } \\
\hline \multirow[t]{3}{*}{0} & .25 & 644 & 14 & 639 & 13 & -5 & 5 \\
\hline & .50 & 626 & 19 & 644 & 19 & $18^{* * *}$ & 5 \\
\hline & .75 & 576 & 13 & 601 & 14 & $25^{* * *}$ & 5 \\
\hline \multirow[t]{3}{*}{200} & .25 & 587 & 13 & 592 & 12 & 5 & 3 \\
\hline & .50 & 551 & 13 & 577 & 13 & $26^{* * *}$ & 5 \\
\hline & .75 & 531 & 14 & 570 & 13 & $39^{* * *}$ & 6 \\
\hline \multirow[t]{3}{*}{1,000} & .25 & 533 & 12 & 513 & 9 & $-20^{* * * *}$ & 4 \\
\hline & .50 & 511 & 9 & 507 & 9 & -4 & 3 \\
\hline & .75 & 495 & 12 & 514 & 13 & $19^{* * * *}$ & 8 \\
\hline
\end{tabular}

Note- $\mathrm{APE}=$ mean reaction time on incongruent trials minus mean reaction time on congruent trials. ${ }^{*} p<.05 .{ }^{* *} p<.01 .{ }^{* * * *} p<.005$ (two-sided $t$ tests). 
analyses revealed that this three-way interaction was due to the fact that in the evaluative categorization task, the effect of affective congruency was more pronounced in the 200-msec-SOA condition than in the 0-msec-SOA condition $[F(1,173)=8.24, p<.005]$, whereas, in the naming task, the effect of affective congruency in the 0 -msec condition was not statistically different from the effect of affective congruency in the 200-msec condition $[F(1,173)=$ $1.79, p=.18] .^{5}$

\section{Error Data}

Detailed descriptive statistics, as well as significance tests for the affective priming effects in each task $\times$ $\mathrm{CP} \times \mathrm{SOA}$ condition (two-sided $t$ tests), are provided in Table 2 . The main effect of affective congruency reached significance $[F(1,173)=56.44, p<.001]$, and the effect of affective congruency proved to be significant in both the evaluative categorization task $[F(1,173)=63.82, p<$ $.001]$ and the naming task $[F(1,173)=6.87, p<.01]$. In line with the reaction time data, the crucial three-way interaction between task, affective congruency, and $\mathrm{CP}$ again reached significance $[F(2,173)=7.17, p<.005]$. As was expected, planned comparisons revealed that this three-way interaction was due to the fact that the effect of affective congruency increased as a function of increasing proportions of affectively congruent trials in the evaluative categorization task $[F(1,173)=41.25, p<.001]$, but not in the naming task $[F(1,173)=1.25, p=.27]$. Accordingly, separate analyses were performed for each task to assess the $\mathrm{CP}$ effects in more detail. In the evaluative categorization task, the linear effect of the $\mathrm{CP}$ on the magnitude of the affective congruency effect was significant in the 0 -msec-SOA condition $[F(1,86)=10.11, p<$ $.005]$, the 200-msec-SOA condition $[F(1,86)=20.39$, $p<.001]$, and the 1,000 -msec-SOA condition $[F(1,86)=$ $4.86, p<.05]$. In contrast, in the naming task, the $\mathrm{CP}$ effect failed to reach significance in each SOA condition (all $F$ s $<2.41$, all $p$ s $>.12$ ). ${ }^{6}$

In line with the reaction time data, the overall MANOVA also revealed a significant interaction between affective congruency and SOA $[F(2,172)=11.92, p<.001]$. Planned comparisons showed that the effect of affective congruency was significant in the 0 -msec-SOA condition $[F(1,173)=36.32, p<.001]$ and the 200-msec-SOA condition $[F(1,173)=35.11, p<.001]$, but not in the 1,000 -msec-SOA condition. It should be noted, however, that the affective congruency effect did approach significance in the 1,000-msec condition $[F(1,173)=3.40, p=$ .07]. Further analyses revealed that this marginally significant effect was entirely due to the fact that the effect of affective congruency approached significance in the 1,000 -msec condition of the evaluative categorization task $[F(1,86)=2.81, p=.097]$. In contrast, the affective congruency effect was completely absent in the $1,000-\mathrm{msec}$ condition of the naming task $(F<1)$. Finally, although the effect of affective congruency was only numerically larger in the 200-msec-SOA condition than in the 0-msecSOA condition $(F<1)$, the three-way interaction between task, SOA, and affective congruency again approached significance $[F(2,172)=2.86, p=.07] .^{7}$
Table 2

Error Data: Mean Percentages of Errors and Mean Affective Priming Effects (APEs) As a Function of Response Condition, Stimulus Onset Asynchrony (SOA), Congruency Proportion (CP), and Affective Congruency

\begin{tabular}{|c|c|c|c|c|c|c|c|}
\hline \multirow{3}{*}{$\begin{array}{c}\mathrm{SOA} \\
(\mathrm{msec})\end{array}$} & \multirow[b]{3}{*}{$\mathrm{CP}$} & \multicolumn{4}{|c|}{ Affective Congruency } & & \\
\hline & & \multicolumn{2}{|c|}{ Congruent } & \multicolumn{2}{|c|}{ Incongruent } & \multicolumn{2}{|c|}{ APE } \\
\hline & & $M$ & $\overline{S E}$ & $M$ & $\overline{S E}$ & $M$ & $S E$ \\
\hline \multicolumn{8}{|c|}{ Naming } \\
\hline \multirow[t]{3}{*}{0} & .25 & 3.1 & 0.6 & 3.9 & 0.6 & 0.8 & 0.9 \\
\hline & .50 & 3.5 & 0.8 & 4.2 & 0.6 & 0.6 & 0.7 \\
\hline & .75 & 2.8 & 0.5 & 5.7 & 1.0 & 2.9 & 1.1 \\
\hline \multirow[t]{3}{*}{200} & .25 & 1.9 & 0.4 & 2.7 & 0.5 & 0.8 & 0.6 \\
\hline & .50 & 2.5 & 0.5 & 3.6 & 0.6 & 1.1 & 0.7 \\
\hline & .75 & 2.7 & 0.5 & 4.7 & 1.0 & 2.0 & 0.9 \\
\hline \multirow[t]{3}{*}{1,000} & .25 & 1.3 & 0.5 & 1.9 & 0.3 & 0.6 & 0.4 \\
\hline & .50 & 2.2 & 0.4 & 1.8 & 0.4 & -0.3 & 0.6 \\
\hline & .75 & 1.9 & 0.5 & 2.4 & 0.6 & 0.5 & 0.8 \\
\hline \multicolumn{8}{|c|}{ Evaluation } \\
\hline \multirow[t]{3}{*}{0} & .25 & 5.7 & 1.5 & 6.6 & 1.6 & 0.9 & 1.1 \\
\hline & .50 & 4.4 & 0.9 & 8.8 & 1.2 & $4.4^{* * *}$ & 1.0 \\
\hline & .75 & 5.9 & 0.9 & 12.4 & 1.6 & $6.5^{\text {*** }}$ & 1.5 \\
\hline \multirow[t]{3}{*}{200} & .25 & 4.6 & 0.1 & 4.8 & 1.5 & 0.2 & 0.9 \\
\hline & .50 & 4.3 & 0.8 & 7.4 & 1.2 & $3.1^{*}$ & 0.9 \\
\hline & .75 & 4.1 & 0.6 & 13.9 & 2.5 & $9.8^{\text {*** }}$ & 2.2 \\
\hline \multirow[t]{3}{*}{1,000} & .25 & 3.0 & 0.6 & 3.1 & 0.7 & 0.1 & 0.5 \\
\hline & .50 & 4.2 & 0.7 & 3.8 & 0.7 & -0.4 & 0.7 \\
\hline & .75 & 3.8 & 0.6 & 7.1 & 1.6 & $3.2^{* *}$ & 1.5 \\
\hline
\end{tabular}

Note-APE $=$ percentage of errors on incongruent trials minus percentage of errors on congruent trials. ${ }^{*} p<.05 .{ }^{* *} p<.005 .{ }^{* * * *} p<.001$ (two-sided $t$ tests)

In sum, it can be concluded that the error data corroborate the reaction time data. To further substantiate this assertion, we calculated the correlation between the affective priming effects that were found in the error data and the reaction time data for each task $\times \mathrm{CP} \times \mathrm{SOA}$ condition (see Tables 1 and 2). As was expected, this correlation was substantial $(r=.78, p<.001)$, corroborating the view that the same pattern of results was found in the reaction time data and the error data.

\section{DISCUSSION}

In line with the hypothesis that humans are endowed with an evaluative decision mechanism that allows them to automatically and unconditionally evaluate all incoming stimulus information, affective priming studies have demonstrated that valenced target stimuli are responded to more quickly after the presentation of an affectively related prime stimulus than after the presentation of an affectively unrelated prime stimulus. Although several authors have claimed that such an affective priming effect can be explained only on the basis of processes that operate at a response selection stage (e.g., De Houwer et al., 2002; Klauer, 1998; Klauer et al., 1997; Klinger et al., 2000; Musch et al., 2004; Rothermund \& Wentura, 1998; Wentura, 1999, 2000), we have argued that processes operating at an encoding level might also contribute to the affective priming effect (see also Bargh et al., 1996; Chen \& Bargh, 1999; De Houwer et al., 2001; De Houwer \& Randell, 2004; Duckworth et al., 2002; Ferguson et al., 
2005; Spruyt et al., 2002; see also Bargh, 1997). According to such an encoding account, affectively polarized prime stimuli preactivate the memory representations of affectively related targets, thus making it easier to encode targets with the same valence than to encode targets with a different valence.

We have reported the results of an experiment in which we orthogonally manipulated the $\mathrm{CP}(.25, .50$, and .75) and the $\operatorname{SOA}(0,200$, and $1,000 \mathrm{msec})$ in the naming task and the evaluative categorization task. On the basis of the hypothesis that affective priming effects that are obtained with the naming task are produced by processes that operate at an encoding stage, we predicted that at short SOAs, the affective priming effect in the naming task would be unaffected by variations in the CP (see also Musch et al., 2004; Neely, 1991; Perea \& Rosa, 2002). In contrast, assuming that affective priming effects that are obtained with the evaluative categorization task are influenced by processes that operate at a response selection stage, we expected to find clear CP effects at short SOAs in the evaluative categorization task. These predictions were confirmed by the experimental observations.

Interestingly, the response latency data also revealed a significant triple interaction between task, SOA, and affective congruency. This three-way interaction was due to the fact that in the evaluative categorization task, the affective priming effect was more pronounced in the 200msec-SOA condition than in the 0 -msec-SOA condition, whereas in the naming task, the affective priming effect was numerically (but not statistically) more pronounced in the 0 -msec-SOA condition than in the 200-msec-SOA condition. An analysis of the error data revealed similar effects. This pattern of results provides additional support for our hypotheses. That is, assuming that response selection can take place only after the identity of the instigating stimuli has been processed to some extent, one would, indeed, predict a buildup of the affective priming effect from the 0 -msec-SOA condition to the 200-msec-SOA in a task that is strongly influenced by processes that operate at a response selection stage. In contrast, one would not expect such a buildup (or even a decrease due to activation decay) in a task that is unaffected by response selection processes.

The results that were obtained at the long SOA of $1,000 \mathrm{msec}$ are also important for the discussion concerning the underlying nature of the affective priming effect. Previous research has demonstrated that affective priming effects are most pronounced at short SOAs and even disappear at longer SOAs (e.g., Fazio et al., 1986; Hermans et al., 2001; Klauer et al., 1997). It has been argued that this finding provides corroborating evidence for the hypothesis that affective priming effects are based on fast-acting, automatic processes. Indeed, if affective priming effects were produced by controlled processes, one would expect that giving participants more time to actively retrieve their attitudes toward the primes would enhance the affective priming effect (Fazio, 2001; Hermans et al., 2001). In line with this reasoning, irrespective of whether the participants were instructed to name the targets or to categorize them on the basis of their valence, affective priming effects were absent at the SOA of $1,000 \mathrm{msec}$ when the $\mathrm{CP}$ was .50 . However, when the SOA was $1,000 \mathrm{msec}$, the data of the evaluative categorization task also revealed a significant $\mathrm{CP}$ effect. Although at odds with the findings of Klauer et al. (1997), this pattern of results is in accordance with previous studies that have demonstrated that priming can be affected by slow-acting, controlled processes at long SOAs (e.g., de Groot, 1984; den Heyer et al., 1983; Neely, 1991; Neely et al., 1989; Perea \& Rosa, 2002; Seidenberg et al., 1984; Tweedy et al., 1977). Also, the item analysis of the response latency data of the naming task revealed a reversed $\mathrm{CP}$ effect at the SOA of $1,000 \mathrm{msec}$ (see note 4). This (unexpected) finding might be accounted for by assuming (1) that the participants in the $.25-\mathrm{CP}$ condition and the .75-CP condition noticed that the valence of the targets could be predicted on the basis of the valence of the primes and (2) that they attempted to actively overcorrect for the influence of the primes (see J. Glaser \& Banaji, 1999; Greenwald \& Banaji, 1995; Strack et al., 1993). On the other hand, given that the latter result was not corroborated by the participant analysis of the response latency data or by the analyses of the error data, it is probably wise not to attach too much weight to it.

To summarize, the present study strongly suggests (1) that affective priming effects that are obtained with the evaluative categorization task and affective priming effects that are obtained with the naming task are qualitatively different as far as the nature of the underlying mechanisms is concerned and (2) that processes that operate at an encoding level do contribute to the affective priming effect. Nevertheless, some prudence is in order when interpreting the naming data in the present study. First of all, it should be emphasized (1) that the number of primes and targets was relatively small (12 primes and 16 targets), (2) that each stimulus was presented several times, and (3) that the targets were also presented during the practice phases. In other words, the memory representations of both the primes and the targets must have been highly activated throughout the entire experiment. For these reasons, one cannot rule out the possibility that processes operating at an encoding level come into play only if the memory representations of the presented stimuli are already preactivated to some extent (see also Kahneman \& Treisman, 1984). In fact, such a restricted encoding account of affective priming would be less difficult to reconcile with existing memory models than would the general hypothesis that any given stimulus can preactivate the memory representation of any other, similarly valenced stimulus, irrespective of the activation level of the memory representations involved. Consider, for instance, a traditional spreading activation model in which concepts are represented as nodes in a vast network of interconnected nodes (e.g., Collins \& Quillian, 1969; W. R. Glaser $\&$ M. O. Glaser, 1989). Within such a framework, it could be argued that affective priming of naming responses is due to the fact (1) that the activation caused by the presentation of the prime automatically spreads to all similarly valenced memory representations (e.g., Bower, 1991) and (2) that the encoding of a stimulus is facilitated when its corresponding concept node is preactivated (e.g., Ander- 
son, 1983; Collins \& Loftus, 1975). However, stimulus valence is a feature that is shared by numerous concept nodes, whereas the amount of available activation is typically assumed to be limited (e.g., Anderson, 1983). Therefore, it seems unlikely that the activation received by each node would have much effect on the encoding of the corresponding stimulus (the so-called fanning effect; Anderson \& Bower, 1973; see also Bargh et al., 1996; De Houwer \& Randell, 2004; Ferguson \& Bargh, 2003; Spruyt et al., 2002). ${ }^{8}$ However, if it is assumed that "spreading of activation" between memory representations of affectively related stimuli can occur (or is effective) only if these memory representations are already preactivated to some extent, such a difficulty could be avoided.

In this respect, it is important to note that in all the studies that produced significant affective priming of naming responses, both the primes and the targets were repeatedly presented (Bargh et al., 1996; Berner \& Maier, 2004; De Houwer et al., 2001; Giner-Sorolla et al., 1999; J. Glaser \& Banaji, 1999; Hermans et al., 1994, 2001; Maier, Berner, \& Pekrun, 2003; Spruyt et al., 2002; Spruyt, Hermans, De Houwer, \& Eelen, 2004). In contrast, Klauer and Musch (2001) failed to obtain significant affective priming in a word-word naming task when so-called infinite stimulus sets were used (i.e., no stimulus was presented more than once). Clearly, this pattern of results is compatible with the hypothesis that affective priming of naming responses can occur only if primes and targets are repeatedly presented. However, Klauer and Musch (2001) also failed to obtain significant affective priming effects when they repeatedly presented a small number of primes and targets. It thus remains to be seen whether stimulus repetition is or is not a prerequisite for obtaining significant affective priming of naming responses. Accordingly, it would be worthwhile to replicate the present study with infinite stimulus sets. Such a study would also be interesting for a second reason. Despite the fact that affective priming in our experiment reached significance in both the item analyses and the participant analyses, one could still speculate about the extent to which the observed priming effects were caused by unintended perceptual and/or nonaffective semantic relations between the primes and the targets. Finding a significant affective priming effect when very large stimulus sets are used would render such a critique less plausible.

A second issue that requires consideration concerns the modality of our stimulus materials. Whereas most studies in which the affective priming effect in the naming task has been examined have used words as primes and targets (but see Spruyt et al., 2002), we employed a picture-naming task. Results obtained by De Houwer et al. (2001) suggest that this difference may not be trivial. In line with several other word-naming studies (see above), these authors failed to obtain significant affective priming of word-naming responses under standard presentation conditions. However, when visually degraded target words were used, they readily obtained strong affective priming effects. As was suggested by Klauer and Musch (2003), this pattern of results can be accounted for if it is assumed (1) that naming a visually degraded target word requires a decision about the target identity and (2) that this decision is biased at a postlexical level by the affective relationship between the primes and the targets (see also Klauer \& Musch, 2002; Wentura, 2000). More specifically, Klauer and Musch (2003) argued that affectively congruent prime-target pairs elicit a spontaneous feeling of plausibility that might facilitate the decision about whether an internally represented candidate target is, indeed, the correct target to be named. Conversely, they argued that affectively incongruent prime-target pairs elicit a spontaneous feeling of implausibility that might inhibit such a decision (see, also, Klauer \& Musch, 2002; Wentura, 2000). Importantly, to the extent that picture naming is less well practiced than word naming (e.g., MacLeod, 1991), it could be hypothesized that picture naming also involves a decision about the target identity. If so, a similar process may be at play in the picture-naming task (Klauer \& Musch, 2003). Alternatively, it has also been argued that participants may use a compound cue consisting of the target and the prime to access memory if target identification is difficult (e.g., Whittlesea \& Jacoby, 1990; see also Hutchison, 2003). According to such an account, priming effects result from the fact that the primes and the targets are co-processed, rather than from the fact that the primes preactivate the memory representations of related targets. It should be noted, however, that reliable affective priming of word-naming responses can be obtained if pictures are used as primes (Giner-Sorolla et al., 1999; Spruyt et al., 2002). Clearly, this finding argues against such alternative accounts. ${ }^{9}$

A final issue concerns the relationship between processes that operate at an encoding level and processes that operate at a response selection stage. Because these processes are assumed to operate at different levels, it could be argued that their effects should be completely independent of each other. Our findings are compatible with such a view. For instance, consider the results that were found at short SOAs in the .25-CP condition of the evaluative categorization task (see Tables 1 and 2). In these conditions, no affective priming effects were obtained, whereas research with the Stroop paradigm has demonstrated that significant reversed Stroop effects (i.e., incompatible stimuli being responded to more quickly than compatible stimuli) emerge when conflicting stimuli occur more often than compatible stimuli (e.g., Logan \& Zbrodoff, 1979). It could be argued that the null results that emerged at short SOAs in the .25$\mathrm{CP}$ condition of the evaluative categorization task were due to the fact that, similar to what is found in the Stroop task, a reversed affective priming effect was produced by processes that operate at a response selection stage, whereas processes that operate at an encoding level produced a standard affective priming effect. In other words, it could be argued that both processes have additive effects. However, such a view is incompatible with the findings of De Houwer et al. (2002) and Klinger et al. (2000). As has been explained above, they failed to obtain significant affective priming when participants were asked to categorize the targets on the basis of a nonaffective semantic feature. Despite the fact that the primes cannot trigger task-relevant response tendencies in the nonaffective semantic categori- 
zation task, one would still expect to find affective priming in this task on the basis of an encoding account of affective priming. At present, we can only speculate about ways to reconcile the encoding account of affective priming with the results from such nonaffective semantic categorization studies. Therefore, future research should continue to explore the processes that underlie the affective priming effect and how they interact (Fazio, 2001).

\section{AUTHOR NOTE}

Correspondence concerning this article should be addressed to A. Spruyt, who is now at Ghent University, H. Dunantlaan 2, B-9000 Ghent, Belgium (e-mail: adriaan.spruyt@ugent.be).

Note-This article was accepted by the previous editorial team, when Colin M. MacLeod was Editor.

\section{REFERENCES}

ANDERSON, J. R. (1983). The architecture of cognition. Cambridge, MA: Harvard University Press.

ANDERSON, J. R., \& Bower, G. H. (1973). Human associative memory. Washington, DC: Winston.

BARGH, J. A. (1996). Automaticity in social psychology. In E. T. Higgins \& A. W. Kruglanski (Eds.), Social psychology: Handbook of basic principles (pp. 169-183). New York: Guilford.

BARGH, J. A. (1997). The automaticity of everyday life. In R. S. Wyer, Jr. (Ed.), The automaticity of everyday life: Advances in social cognition (Vol. 10, pp. 1-61). Mahwah, NJ: Erlbaum.

Bargh, J. A., Chaiken, S., Raymond, P., \& Hymes, C. (1996). The automatic evaluation effect: Unconditional automatic attitude activation with a pronunciation task. Journal of Experimental Social Psychology, 32, 104-128.

Bargh, J. A., LitT, J., Pratto, F., \& Spielman, L. A. (1989). On the preconscious evaluation of social stimuli. In A. F. Bennett \& K. M. McConkey (Eds.), Cognition in individual and social contexts: Proceedings of the XXIV International Congress of Psychology (Vol. 3, pp. 357-370). Amsterdam: Elsevier.

BERnER, M. P., \& MAIER, M. A. (2004). The direction of affective priming as a function of trait anxiety when naming target words with regular and irregular pronunciation. Experimental Psychology, 51, 180-190.

Bower, G. H. (1991). Mood congruity of social judgments. In J. P. Forgas (Ed.), Emotion and social judgments (International Series in Experimental Social Psychology, pp. 31-53). Oxford: Pergamon.

CENTER for the Psychophysiological Study of Emotion and AtTENTION (1994). The International Affective Picture System. Gainesville: University of Florida, Center for Research in Psychophysiology.

Chen, M., \& BARgh, J. A. (1999). Consequences of automatic evaluation: Immediate behavioral predispositions to approach or avoid the stimulus. Personality \& Social Psychology Bulletin, 25, 215-224.

Cohen, J. D., DunBaR, K., \& MCClelland, J. L. (1990). On the control of automatic processes: A parallel distributed processing account of the Stroop effect. Psychological Review, 97, 332-361.

Collins, A. M., \& LoFTUS, E. F. (1975). A spreading activation theory of semantic processing. Psychological Review, 82, 407-428.

Collins, A. M., \& Quillian, M. R. (1969). Retrieval time from semantic memory. Journal of Verbal Learning \& Verbal Behavior, 8 , 240-247.

DALRYMPle-Alford, E. C., \& Budayr, B. (1966). Examination of some aspects of the Stroop color-word test. Perceptual \& Motor Skills, 23, 1211-1214.

DALrymple-Alford, E. C., \& MarmureK, H. H. C. (1999). Semantic priming in fully recurrent network models of lexical knowledge. Journal of Experimental Psychology: Learning, Memory, \& Cognition, 25, 758-775.

DE Groot, A. M. B. (1984). Primed lexical decision: Combined effects of the proportion of related prime-target pairs and the stimulus-onset asynchrony of prime and target. Quarterly Journal of Experimental Psychology, 36A, 253-280.
De Houwer, J. (2003). A structural analysis of indirect measures of attitudes. In J. Musch \& K. C. Klauer (Eds.), The psychology of evaluation: Affective processes in cognition and emotion (pp. 219-244). Mahwah, NJ: Erlbaum.

De Houwer, J., \& Hermans, D. (1994). Differences in the affective processing of words and pictures. Cognition \& Emotion, 8, 1-20.

De Houwer, J., Hermans, D., \& Eelen, P. (1998). Affective and identity priming with episodically associated stimuli. Cognition \& Emotion, 12, 145-169.

De Houwer, J., Hermans, D., Rothermund, K., \& Wentura, D. (2002). Affective priming of semantic categorization responses. Cognition \& Emotion, 16, 643-666.

De Houwer, J., Hermans, D., \& Spruyt, A. (2001). Affective priming of pronunciation responses: Effects of target degradation. Journal of Experimental Social Psychology, 37, 85-91.

DE HOUWER, J., \& RANDELl, D. (2004). Robust affective priming effects in a conditional pronunciation task: Evidence for the semantic representation of evaluative information. Cognition \& Emotion, 18, 251-264.

de $\overline{\text { Heyer}}$, K., Briand, K., \& Dannenbring, G. L. (1983). Strategic factors in a lexical-decision task: Evidence for automatic and attention-driven processes. Memory \& Cognition, 11, 374-381.

Draine, S. C., \& Greenwald, A. G. (1998). Replicable unconscious semantic priming. Journal of Experimental Psychology: General, 127, 286-303.

DúcKWORTh, K. L., Bargh, J. A., Garcia, M., \& Chaiken, S. (2002). The automatic evaluation of novel stimuli. Psychological Science, 13, 513-519.

FA ZIO, R. H. (2001). On the automatic activation of associated evaluations: An overview. Cognition \& Emotion, 15, 115-141.

Fazio, R. H., Sanbonmatsu, D. M., Powell, M. C., \& Kardes, F. R. (1986). On the automatic activation of attitudes. Journal of Personality \& Social Psychology, 50, 229-238.

FERGUSON, M. J., \& BARGH, J. A. (2003). The constructive nature of automatic evaluation. In J. Musch \& K. C. Klauer (Eds.), The psychology of evaluation: Affective processes in cognition and emotion (pp. 169-188). Mahwah, NJ: Erlbaum.

Ferguson, M. J., Bargh, J. A., \& NAYAK, D. A. (2005). After-affects: How automatic evaluations influence the interpretation of subsequent, unrelated stimuli. Journal of Experimental Social Psychology, 41, 182-191.

Fiske, S. T., \& PavelchaK, M. A. (1986). Category-based versus piecemeal-based affective responses: Developments in schematriggered affect. In R. M. Sorrentino \& E. T. Higgins (Eds.), Handbook of motivation and cognition: Foundations of social behavior (pp. 167-203). New York: Guilford.

Fox, E. (1995). Negative priming from ignored distractors in visual selection: A review. Psychonomic Bulletin \& Review, 2, 145-173.

GARDNER, R. M. (1985). The reverse affect test: A new interference task. Perceptual \& Motor Skills, 60, 384-386.

GiNER-SOROLLA, R., GARCíA, M. T., \& BARGH, J. A. (1999). The automatic evaluation of pictures. Social Cognition, 17, 76-96.

Glaser, J., \& BANAJI, M. R. (1999). When fair is foul and foul is fair: Reverse priming in automatic evaluation. Journal of Personality \& Social Psychology, 77, 669-687.

GLASER, W. R. (1992). Picture naming. Cognition, 42, 61-105.

Glaser, W. R., \& Glaser, M. O. (1989). Context effects in Stroop-like word and picture processing. Journal of Experimental Psychology: General, 118, 13-42.

GREENWALD, A. G., \& BANAJI, M. R. (1995). Implicit social cognition: Attitudes, self-esteem, and stereotypes. Psychological Review, 102, 4-27.

GreEnWald, A. G., Klinger, M. R., \& LiU, T. J. (1989). Unconscious processing of dichoptically masked words. Memory \& Cognition, 17, $35-47$.

Greenwald, A. G., Klinger, M. R., \& Schuh, E. S. (1995). Activation by marginally perceptible ("subliminal") stimuli: Dissociation of unconscious from conscious cognition. Journal of Experimental Psychology: General, 124, 22-42.

HERMANS, D. (1996). Automatische stimulusevaluatie: Een experimentele analyse van de voorwaarden voor evaluatieve stimulusdiscriminatie aan de hand van het affectieve-primingparadigma [Automatic stimulus evaluation: An experimental analysis of the preconditions 
for evaluative stimulus discrimination using an affective priming paradigm]. Unpublished doctoral dissertation, University of Leuven, Belgium.

Hermans, D., Baeyens, F., \& Eelen, P. (1998). Odours as affectiveprocessing context for word evaluation: A case of cross-modal affective priming. Cognition \& Emotion, 12, 601-613.

Hermans, D., Clarysse, J., Baeyens, F., \& Spruyt, A. (2003). Affect (Version 3.0) [Computer software]. Leuven: University of Leuven. Retrieved from www.psy.kuleuven.ac.be/leerpsy/affect.

Hermans, D., Crombez, G., \& Eelen, P. (2000). Automatic attitude activation and efficiency: The fourth horseman of automaticity. Psychologica Belgica, 40, 3-22.

Hermans, D., De Houwer, J., \& Eelen, P. (1994). The affective priming effect: Automatic activation of evaluative information in memory. Cognition \& Emotion, 8, 515-533.

Hermans, D., De Houwer, J., \& Eelen, P. (2001). A time course analysis of the affective priming effect. Cognition \& Emotion, 15, 143-165.

Hermans, D., Spruyt, A., De Houwer, J., \& Eelen, P. (2003). Affective priming with subliminally presented pictures. Canadian Journal of Experimental Psychology, 57, 97-114.

HUTCHISON, K. A. (2003). Is semantic priming due to association strength or feature overlap? A microanalytic review. Psychonomic Bulletin \& Review, 10, 785-813.

KAHNEMAN, D., \& Treisman, A. (1984). Changing views of attention and automaticity. In R. Parasuraman \& D. R. Davies (Eds.), Varieties of attention (pp. 29-61). Orlando, FL: Academic Press.

Kawamoto, A. H. (1988). Distributed representations of ambiguous words and their resolution in a connectionist network. In S. L. Small, G. W. Cottrell, \& M. K. Tanenhaus (Eds.), Lexical ambiguity resolution: Perspectives from psycholinguistics, neuropsychology, and artificial intelligence (pp. 195-228). San Mateo, CA: Morgan Kaufmann.

Klauer, K. C. (1998). Affective priming. European Review of Social Psychology, 8, 63-107.

Klauer, K. C., \& Musch, J. (2001). Does sunshine prime loyal? Affective priming in the naming task. Quarterly Journal of Experimental Psychology, 54, 727-751.

Klauer, K. C., \& Musch, J. (2002). Goal-dependent and goalindependent effects of irrelevant evaluations. Personality \& Social Psychology Bulletin, 28, 802-814.

KLAuer, K. C., \& Musch, J. (2003). Affective priming: Findings and theories. In J. Musch \& K. C. Klauer (Eds.), The psychology of evaluation: Affective processes in cognition and emotion (pp. 7-49). Mahwah, NJ: Erlbaum.

Klauer, K. C., Roßnagel, C., \& Musch, J. (1997). List-context effects in evaluative priming. Journal of Experimental Psychology: Learning, Memory, \& Cognition, 23, 246-255.

KLInger, M. R., Burton, P. C., \& Pitts, G. S. (2000). Mechanisms of unconscious priming: I. Response competition, not spreading activation. Journal of Experimental Psychology: Learning, Memory, \& Cognition, 26, 441-455.

LAZARUS, R. S. (1991). Emotion and adaptation. New York: Oxford University Press.

LeDoux, J. E. (1989). Cognitive-emotional interactions in the brain. Cognition \& Emotion, 3, 267-289.

LoGAN, G. D. (1980). Attention and automaticity in Stroop and priming tasks: Theory and data. Cognitive Psychology, 12, 523-553.

Logan, G. D., \& ZBrodoFf, N. J. (1979). When it helps to be misled: Facilitative effects of increasing the frequency of conflicting stimuli in a Stroop-like task. Memory \& Cognition, 7, 166-174.

Lowe, D. G., \& MitTerER, J. O. (1982). Selective and divided attention in a Stroop task. Canadian Journal of Psychology, 36, 684-700.

MacLeod, C. M. (1991). Half a century of research on the Stroop effect: An integrative review. Psychological Bulletin, 109, 163-203.

Maier, M. A., Berner, M. P., \& PeKrun, R. (2003). Directionality of affective priming: Effects of trait anxiety and activation level. Experimental Psychology, 50, 116-123.

Masson, M. E. J. (1995). A distributed model of semantic priming. Journal of Experimental Psychology: Learning, Memory, \& Cognition, 21, 3-23.

MASSON, M. E. J. (1999). Interactive processes in word identification: Modeling context effects in a distributed memory system. In R. M.
Klein \& P. A. McMullen (Eds.), Converging methods for understanding reading and dyslexia (pp. 373-411). Cambridge, MA: MIT Press.

MaY, C. P., KANE, M. J., \& Hasher, L. (1995). Determinants of negative priming. Psychological Bulletin, 118, 35-54.

McRae, K., DE SA, V. R., \& SeIDENBERG, M. S. (1997). On the nature and scope of featural representations of word meaning. Journal of Experimental Psychology: General, 126, 99-130.

MURPHY, S. T., \& ZAJONC, R. B. (1993). Affect, cognition, and awareness: Affective priming with optimal and suboptimal stimulus exposures. Journal of Personality \& Social Psychology, 64, 723-739.

Musch, J., \& KLAUER, K. C. (2001). Locational uncertainty moderates affective congruency effects in the evaluative decision task. Cognition \& Emotion, 15, 167-188.

MUSCH, J., Klauer, K. C., \& Mierke, J. (2004). Automatic and strategic components of affective priming. Unpublished manuscript.

NeELy, J. H. (1977). Semantic priming and retrieval from lexical memory: Roles of inhibitionless spreading activation and limitedcapacity attention. Journal of Experimental Psychology: General, 106, 226-254.

NEELY, J. H. (1991). Semantic priming effects in visual word recognition: A selective review of current findings and theories. In D. Besner \& G. W. Humphreys (Eds.), Basic processes in reading: Visual word recognition (pp. 264-336). Hillsdale, NJ: Erlbaum.

Neely, J. H., Keefe, D. E., \& Ross, K. L. (1989). Semantic priming in the lexical decision task: Roles of prospective prime-generated expectancies and retrospective semantic matching. Journal of Experimental Psychology: Learning, Memory, \& Cognition, 15, 1003-1019.

NoRRIS, D. (1986). Word recognition: Context effects without priming. Cognition, 22, 93-136.

ÖHMAN, A. (1987). The psychophysiology of emotion: An evolutionarycognitive perspective. Advances in Psychophysiology, 2, 79-127.

Öhman, A. (1988). Preattentive processes in the generation of emotions. In V. Hamilton, G. H. Bower, \& N. Frijda (Eds.), Cognitive perspectives on emotion and motivation (pp. 127-143). Dordrecht: Kluwer.

Ortony, A., Clore, G. L., \& Collins, A. (1988). The cognitive structure of emotions. Cambridge: Cambridge University Press.

Perea, M., \& Rosa, E. (2002). Does the proportion of associatively related pairs modulate the associative priming effect at very brief stimulus-onset asynchronies? Acta Psychologica, 110, 103-124.

Rothermund, K., \& Wentura, D. (1998). Ein fairer Test für die Aktivationsausbreitungshypothese: Untersuchung affektiver Kongruenzeffekte in der Stroop-Aufgabe [An unbiased test of a spreading of activation account of affective priming: Analysis of affective congruency effects in the Stroop task]. Zeitschrift für Experimentelle Psychologie, 45, 120-135.

SCHERER, K. R. (1993). Neuroscience projections to current debates in emotion psychology. Cognition \& Emotion, 7, 1-41.

SeidenberG, M. S., Waters, G. S., SANDERS, M., \& LAnger, P. (1984). Pre- and postlexical loci of contextual effects on word recognition. Memory \& Cognition, 12, 315-328.

SMITH, E. R. (1996). What do connectionism and social psychology offer each other? Journal of Personality \& Social Psychology, 70, 893-912.

SpRuYt, A., Hermans, D., De Houwer, J., \& Eelen, P. (2002). On the nature of the affective priming effect: Affective priming of naming responses. Social Cognition, 20, 227-256.

Spruyt, A., Hermans, D., De Houwer, J., \& Eelen, P. (2004). Automatic non-associative semantic priming: Episodic affective priming of naming responses. Acta Psychologica, 116, 39-54.

Spruyt, A., Hermans, D., Pandelaere, M., De Houwer, J., \& EELEN, P. (2004). On the replicability of the affective priming effect in the pronunciation task. Experimental Psychology, 51, 109-115.

Strack, F., Schwarz, N., Bless, H., Kübler, A., \& Wänke, M. (1993). Awareness of the influence as a determinant of assimilation versus contrast. European Journal of Social Psychology, 23, 53-62.

Tweedy, J. R., LAPINSKI, R. H., \& SchVaneveldT, R. W. (1977). Semantic-context effects on word recognition: Influence of varying the proportion of items presented in an appropriate context. Memory \& Cognition, 5, 84-99.

Wentura, D. (1999). Activation and inhibition of affective information: Evidence for negative priming in the evaluation task. Cognition \& Emotion, 13, 65-91. 
Wentura, D. (2000). Dissociative affective and associative priming effects in the lexical decision task: Yes versus no responses to word targets reveal evaluative judgment tendencies. Journal of Experimental Psychology: Learning, Memory, \& Cognition, 26, 456-469.

Wentura, D., \& Rothermund, K. (2003). The "meddling-in" of affective information: A general model of automatic evaluation effects. In J. Musch \& K. C. Klauer (Eds.), The psychology of evaluation: Affective processes in cognition and emotion (pp. 51-86). Mahwah, NJ: Erlbaum.

Whittlesea, B. W. A., \& Jacoby, L. L. (1990). Interaction of prime repetition with visual degradation: Is priming a retrieval phenomenon? Journal of Memory \& Language, 29, 546-565.

ZAJONC, R. B. (1980). Feeling and thinking: Preferences need no inferences. American Psychologist, 35, 151-175.

ZaJONC, R. B. (1984). On the primacy of affect. American Psychologist, 39, 117-123.

\section{NOTES}

1. This observation is especially problematic in the light of the fact that alternative explanations for the affective priming effect in the naming task can be formulated. For example, as has been pointed out by Rothermund and Wentura (1998), there may exist systematic differences in the way positive and negative words are typically pronounced (see also Gardner, 1985; Wentura \& Rothermund, 2003). In that case, one could argue that even in the naming task, affective priming effects are produced by processes that operate at a response selection stage. Although speculative at the moment, such an account is rather appealing because it could parsimoniously explain why affective priming effects can be found in naming tasks, but not when participants are asked to classify the targets on the basis of a nonaffective semantic feature (De Houwer et al., 2002; Klinger et al., 2000).

2. Some of these pictures originated from the International Affective Picture System (IAPS; Center for the Psychophysiological Study of Emotion and Attention, 1994). IAPS numbers: 1030, 1050, 1120, 1201, 1300, 1301, 1302, 1500, 1610, 1750, 1930, 1931, 2070, 2120, 2220, $2565,2800,4490,4611,4534,4651,4672,4680,5030,6250,6350$, $6550,6560,7350,9040$.

3. This participant was assigned to the counterbalancing group that started with the 0-msec-SOA condition in the experiment. Most likely, this participant responded on the basis of the valence of the primes, instead of on the basis of the valence of the targets.

4. An item analysis of the response latency data yielded similar results. That is, the effect of affective congruency was significant in both the evaluative categorization task $[F(1,15)=47.70, p<.001]$ and the naming task $[F(1,15)=43.26, p<.001]$, and the crucial three-way interaction between task, $\mathrm{CP}$, and affective congruency again reached significance $[F(2,14)=10.73, p<.005]$. In the evaluative categorization task, the linear effect of the $\mathrm{CP}$ on the magnitude of the affective congruency effect was significant in the 0 -msec-SOA condition $[F(1,15)=4.85, p<$ $.05]$, the 200-msec-SOA condition $[F(1,15)=19.25, p<.001]$, and the 1,000 -msec-SOA condition $[F(1,15)=17.30, p<.001]$. In contrast, no $\mathrm{CP}$ effects were found in the short-SOA conditions for the naming task ( $p$ s $=.18$ and .68 in the $0-\mathrm{msec}-\mathrm{SOA}$ and the 200-msec-SOA conditions, respectively). Unexpectedly, however, the item analysis did reveal a $r e-$ versed $\mathrm{CP}$ effect in the 1,000-msec-SOA condition for the naming task [i.e., the difference between affectively congruent and affectively incongruent trials decreased as a function of increasing levels of $\mathrm{CP} ; F(1,15)=$ $5.42, p<.05]$. Note, however, that this finding is not corroborated by the results of an item analysis of the error data $(F<1$; see note 6$)$.

5 . The overall MANOVA also revealed a significant, but theoretically irrelevant, main effect of block $[F(2,172)=31.00, p<.001]$ that interacted with the task variable $[F(2,172)=3.68, p<.05]$. Further analysis revealed that this two-way interaction was due to a more pronounced decrease in mean response latency from the first to the second block in the evaluative categorization task than in the naming task $[F(1,173)=4.39$, $p<.05]$. In addition, the overall MANOVA also revealed a significant, but theoretically irrelevant, interaction between the task variable and SOA $[F(2,172)=3.30, p<.05]$.

6. An item analysis of the error data yielded similar results. The effect of affective congruency was significant in both the evaluative categorization task $[F(1,15)=65.00, p<.001]$ and the naming task $[F(1,15)=$ $7.05, p<.05]$, and the crucial three-way interaction between task, $\mathrm{CP}$, and affective congruency again reached significance $[F(2,14)=13.01$, $p<.001]$. Further analyses revealed that in the evaluative categorization task, the linear effect of the $\mathrm{CP}$ on the magnitude of the affective congruency effect was significant in the 0 -msec-SOA condition $[F(1,15)=$ $21.22, p<.001]$, the 200-msec-SOA condition $[F(1,15)=43.25, p<$ $.001]$, and the 1,000 -msec-SOA condition $[F(1,15)=7.96, p<.001]$. In contrast, $\mathrm{CP}$ effects were absent in all the SOA conditions for the naming task (all $F \mathrm{~s}<1.55$, all $p \mathrm{~s}>.23$ ).

7. In line with the reaction time data, the overall MANOVA also revealed a significant main effect of block $[F(2,172)=18.74, p<.001]$.

8 . Several authors have suggested that this problem may be sidestepped by adopting a distributed memory model of semantic priming (e.g., De Houwer \& Randell, 2004; Ferguson \& Bargh, 2003; Spruyt et al., 2002; Wentura, 1999, 2000). However, we believe that current versions of distributed memory models are just as difficult to reconcile with a general encoding account of affective priming as are localist spreading activation models. According to distributed memory models of semantic priming (e.g., Kawamoto, 1988; Masson, 1995, 1999; McRae, de Sa, \& Seidenberg, 1997), memory representations consist of a pattern of activation across a large number of elemental processing units that need to be iteratively updated each time a new stimulus is presented. Because fewer changes need to be made to the semantic units to form the semantic pattern of a target when there is overlap between the patterns of activation of the prime and the target, these models naturally predict that the encoding of a target will be faster after the presentation of a semantically related prime than after the presentation of a semantically unrelated prime (Masson, 1995, 1999; Smith, 1996; but see Dalrymple-Alford \& Marmurek, 1999). However, semantic priming in a distributed memory model can occur only if the amount of overlap in the semantic-processing units is substantial. In the simulation studies of Masson (1995), for example, the amount of semantic overlap between semantically related prime-target pairs was $67.5 \%$ (54 out of 80 semantic-processing units). Therefore, given that affective priming is based on the affective relationship between the primes and the targets only (e.g., Spruyt, Hermans, De Houwer, \& Eelen, 2004), one would have to assume that affective stimulus information is represented by an implausibly large proportion of the available processing units.

9. Yet another account for priming in the naming task was proposed by Norris (1986). According to his plausibility-checking theory, each target stimulus activates a set of candidate targets prior to conscious recognition. Each of these candidate targets is then checked to determine its plausibility, given the priming context. If an item in the candidate set is related to the context (i.e., contextually plausible), its recognition threshold is lowered; if it is unrelated to the context (i.e., contextually implausible), its recognition threshold is raised. However, as has been explained by Neely (1991), it can be assumed that participants are more likely to utilize the plausibility-checking mechanism as the proportion of trials on which the primes and the targets are related increases. Therefore, given that affective priming effects were unaffected by the $\mathrm{CP}$ in the naming conditions in our experiment when the SOA was short, it seems unlikely that plausibility checking was responsible for the affective priming effects that emerged in the naming conditions in our experiment. 
APPENDIX

Target Names and Descriptions of the Prime Stimuli

\begin{tabular}{|c|c|}
\hline Positive & Negative \\
\hline \multicolumn{2}{|c|}{ Target Names } \\
\hline $\begin{array}{l}\text { poesje (kitten) } \\
\text { baby (baby) } \\
\text { bruid (bride) } \\
\text { dolfijn (dolphin) } \\
\text { kerstboom (Christmas tree) } \\
\text { teddybeer (teddy bear) } \\
\text { bloem (flower) } \\
\text { pup (puppy) }\end{array}$ & $\begin{array}{l}\text { wormen (worms) } \\
\text { lijk (corpse) } \\
\text { spin (spider) } \\
\text { Hitler (Hitler) } \\
\text { vuilnis (litter) } \\
\text { explosie (explosion) } \\
\text { schedels (skulls) } \\
\text { pistool (pistol) }\end{array}$ \\
\hline \multicolumn{2}{|c|}{ Prime Stimuli } \\
\hline $\begin{array}{l}\text { sunset over beach } \\
\text { colorful balloon in bright sky } \\
\text { exotic landscape with rainbow } \\
\text { nut-cracking squirrel in sunshine } \\
\text { young naked couple } \\
\text { smiling young father with baby }\end{array}$ & $\begin{array}{l}\text { burning house } \\
\text { enraged looking man } \\
\text { man pointing a gun } \\
\text { aggressive dog } \\
\text { man assaulting a woman } \\
\text { attacking shark }\end{array}$ \\
\hline
\end{tabular}

(Manuscript received May 26, 2004;

revision accepted for publication October 25, 2005.) 